American Journal of Immunology 8 (2): 33-37, 2012

ISSN 1553-619X

(C) 2012 Science Publications

\title{
Immunity to Pneumococcal Vaccine in Splenectomized $\beta$-Thalassemia Patients
}

\author{
${ }^{1}$ Abdolreza Sotoodeh Jahromi, \\ ${ }^{1}$ Mohammad Reza Farjam, ${ }^{2}$ Alireza Makarem, \\ ${ }^{2}$ Mohammad Yasin Karami, ${ }^{2}$ Aida Amanat and ${ }^{3}$ Abdoulhossein Madani \\ ${ }^{1}$ Department of Immunology, Faculty of Medicine, \\ ${ }^{2}$ Department of Epidemiology, Student Research Committee, \\ Jahrom University of Medical Sciences, Jahrom, Iran \\ ${ }^{3}$ Department of Epidemiology, Faculty of Health, \\ Hormozgan University of Medical Sciences, Bandar Abbas, Iran
}

\begin{abstract}
Problem statement: Splenectomy is accompanied by a lifelong risk of overwhelming post splenectomy infection, mainly caused by encapsulated bacteria such as Streptococcus pneumoniae. The mortality rate in those infected patients remains high. Therefore the pneumococcal polysaccharide vaccine has been recommended. Approach: To obtain information on the immunity levels of pneumococcal antibody, in splenectomized $\beta$-thalassemia patients in south of Iran. Patients and methods: This descriptive and cross sectional study was carried out on 263 splenectomized $\beta$ thalassemia patients in south of Iran, June 2007-September 2008. Anti-pneumococcal vaccine antibody concentrations were measured by the enzyme-linked immunosorbent assay method. The patients were divided into two groups based on antibody concentrations: Group 1: Hyporesponsiveness patients or non-immune with less than $250 \mathrm{mU} \mathrm{mL}^{-1}$ antibody concentrations and group 2: Immune patients or responder with equal or more than $250 \mathrm{mU} \mathrm{mL}^{-1}$ antibody concentrations. Results: The results showed that 33.80 and $66.20 \%$ of the patients were immune and non-immune to pneumococcal infections, respectively. There was an inverse significant between Immunity level with the period after pneumococcal vaccination $(r=-0.683, p=0.0001)$. Conclusion: These results suggest that a high percentage splenectomized $\beta$-thalassemia patients are poor responders to pneumococcal vaccination. Therefore evaluations immunity levels of pneumococcal vaccine and re-vaccination for pneumococcus are recommended in these patients.
\end{abstract}

Key words: Immune response, peumococcal infection, splenectomy, thalassemia, vaccination

\section{INTRODUCTION}

The term thalassemia (derived from the Greek "Thalassa", which means "the sea" stating to the Mediterranean-and "emia", meaning "related to blood") designates a diverse group of genetic disorders of hemoglobin synthesis characterized by a disturbance of the making of globin chains, leading to anemia, ineffectual erythropoiesis (Weatherall and Clegg, 2001), particularly in some parts of the world like the Mediterranean area, north and west of Africa and the Middle East. Its' worldwide incidence is about 2 per 1,000 newborns while its' prevalence in Iran is 8-4 per 1,000 newborns and frequency of thalassemia gene in Iran is $4-10 \%$ (Ali et al., 2008).
Health wealth is insufficient in most of the countries where the disease is common (Karnon et al., 1999). In most of the countries where $\beta$-thalassemia is common, there is not a realistic situation for these patients. The blood transfusion resource was basic at best and desferrioxamine supply was inconsistent. Full facial and clinical features of the disease from the ineffective bone marrow expansion were presented in most of the patients. Splenomegaly was seen in patients early in their lives and splenectomy was done at a relatively young age. Splenectomy is necessary in $\beta$ thalassemia patients when the spleen develops hyperactive, leading to extreme destruction of erythrocytes and thus growing the need for regular blood transfusions, which in turn outcomes more iron

Corresponding Author: Mohammad Reza Farjam, Department of Immunology, Faculty of Medicine,

Jahrom University of Medical Sciences, Jahrom, Iran 
accumulation. As a result, splenectomy is commonly done (Hoe et al., 1994). Infectious diseases are the second most common cause of mortality and a main cause of morbidity in $\beta$-thalassemia patients (Cadili and Gara, 2008). Some immunological disorders have been reported in $\beta$-thalassemia patients (Gharagozloo et al., 2009) and asplenia is one of the essential causes of immunodeficiency in patients with $\beta$-thalassemia (Ricerca et al., 2009).

As the spleen is more effective at eliminating nonopsonized bacteria, mostly encapsulated organisms, asplenia can lead to immune defects to encapsulated micro-organisms (Cadili and Gara, 2008) and splenectomized $\beta$-thalassemia patients are more at risk of developing sepsis by these encapsulated bacteria. Overwhelming Postsplenectomy Infection (OPSI) is a serious complication of asplenia and is usually caused by encapsulated bacteria (Waghorn, 2001). Over $70 \%$ of all cases of OPSI are due to Streptococcus pneumoniae, even though no more than $5 \%$ of other septic episodes are attributable to this bacterium (Cadili and Gara, 2008). To prevent OPSI, a pneumococcal vaccine with purified capsular polysaccharide from the pneumococcal types that commonly cause infection has been recommended (Austrian, 1977).

Iran splenectomized $\beta$-thalassemia patients are vaccinated with Pneumococcal vaccine (Pneumovax) to prevent OPSI 14 days before splenectomy.

Unfortunately, none of the Iranian splenectomized $\beta$-thalassemia patients have been assessed for immunity level to Streptococcus pneumonia and there is no monitoring for this immunity in these patients in IRAN. This was the first study to determine the antibody response to vaccination for Streptococcus pneumoniae with Pneumococcal vaccine (Pneumovax) in Iranian splenectomized $\beta$-thalassemia patients.

\section{METERIALS AND METHODS}

\section{Patients and methods:}

Patients: A total of $263 \beta$-thalassemia patients who underwent splenectomy and vaccinated with Pneumovax, who were referred to thalassemia centers of in the south of Iran, were enrolled to this descriptive and cross sectional study.

Exclusion criteria for all the patients included: Any immune suppressive therapy in the prior six months and a history of immunodeficiency and Acquired Immunodeficiency Syndrome (AIDS). This study was carried out from June 2007 to September 2008.

The study protocol was reviewed and approved by the Research Ethics Committee of Jahrom University of Medical Sciences and informed consent was obtained from each patient.
Methods: A questionnaire was designed to collect demographic information and medical history of the patients by reviewing the patient's records. All patients vaccinated intramuscularly with a single dose of $0.5 \mathrm{ml}$ of Pneumovax 14 days before splenectomy. Blood samples were taken from the patients and serum samples were stored at $-70^{\circ} \mathrm{C}$ until assayed for antibody measurements. Specific antibodies against Pneumococcal Capsular Polysaccharide (PCP) were measured using the protocol of the third-generation enzyme-linked immunosorbent assay format (Wernette et al., 2003; Mahmoodi et al., 2009).

The assay has been designed to measure the $\mathrm{IgG}$ antibody responses to pneumococcal vaccine incorporating 23 polysaccharides isolated from Streptococcus pneumoniae. These polysaccharides correspond to approximately $80 \%$ of the commonly encountered, virulent serotypes. The levels of serum specific anti-PCP IgG antibodies were determined by an enzyme immunoassay kit (Pneumococcus IgG Immonupotency level/E-DG-MZ-001/04-04, ZenTech, Belgium). In this assay, microwaves were pre-coated with the PCP antigen. Serum samples were tested in accordance with the manufacturer's instructions. Serum samples were diluted 1:510. The titers of anti PCP IgG antibodies were determined with reference to the standard serum included in the kit and were expressed as mili unit/ml (mu/ml). Some reference plasmas with assigned values of anti PCP IgG were used as Calibrators to draw standard curve. The sensitivity of this kit was 6.9 $\mathrm{mU} / \mathrm{mL}$. Serum samples were tested in duplicate.

Corresponding anti PCP IgG antibodies in $\mathrm{mu} / \mathrm{ml}$ are obtained by interpolating the observance of each sample on the calibration curve. According to directions on this kit the result Interpretation was done as follows:

- Lower than $250 \mathrm{mU} \mathrm{mL}^{-1}=$ Deficient in anti PCP IgG antibodies or hyporesponsiveness

- Equal to or more than $250 \mathrm{mU} \mathrm{mL}^{-1}=\operatorname{good}$ response or Immune to pneumococcal infection

- All patients were categorized according to their serum anti-pneumococcal IgG titers

Statistical analysis: Data were analyzed using an SPSS 14.0 software package. Specific antibody titers were expressed as the geometric mean. T test and correlation test were performed for analysis.

\section{RESULTS}

A total of 263 splenectomised $\beta$-thalassemia patients, (133 males and 130 females), aged 18-64 years

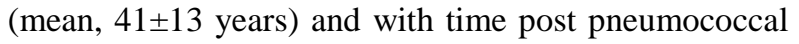
vaccination 12-336 mounts (mean, 106.77 \pm 67.62 ) mounts were evaluated for antibody response to PPV23. 
Am. J. Immunol., 8 (2): 33-37, 2012

Table 1: Demographic and serum anti-pneumococcal $\mathrm{IgG}$ titers for the patients

\begin{tabular}{|c|c|c|c|}
\hline Sex & Age (years) & $\begin{array}{l}\text { Time post } \\
\text { vaccination } \\
\text { (mounts) }\end{array}$ & $\begin{array}{l}\text { Anti- } \\
\text { pneumococcus } \\
\text { IgG }(\mathrm{mU} / \mathrm{ml})\end{array}$ \\
\hline Female $\mathrm{N}=130(49.40 \%)$ & 18.39 & $94.85 \pm 59.00$ & $212.67 \pm 68.72$ \\
\hline Male $\mathrm{N}=133(50.60 \%)$ & $19.25 \pm 6.40$ & $118.42 \pm 73.46$ & $199.00 \pm 74.50$ \\
\hline P-value & 0.214 & 0.004 & 0.123 \\
\hline
\end{tabular}

Table-2: Comparison of Hypo-responsive group Vs responder group

\begin{tabular}{lccc}
\hline Groups & Age (years) & $\begin{array}{l}\text { Time after } \\
\text { vaccination } \\
\text { (mounts) }\end{array}$ & $\begin{array}{l}\text { Anti- } \\
\text { pneumococcus } \\
\text { IgG (mU/mL) }\end{array}$ \\
\hline Hypo-responsive & $19.17 \pm 5.00$ & $133.88 \pm 60.71$ & $167.30 \pm 52.15$ \\
Responder & $18.16 \pm 6.53$ & $53.76 \pm 45.52$ & $280.94 \pm 37.42$ \\
P-Value & 0.165 & $0.0001 *$ & $0.0001 *$ \\
\hline
\end{tabular}

There were found inverse significant correlations between antipneumococcal $\mathrm{IgG}$ titers and time post vaccination $(\mathrm{r}=-0.683, \mathrm{p}=$ $0.0001)$

Demographic and serum anti-pneumococcal IgG titers $(\mathrm{mU} / \mathrm{mL})$ for all patients were summarized in Table 1. All patients were categorized according to their serum anti-pneumococcal IgG titers ( $\mathrm{mU} / \mathrm{mL}$ ) to two groups:

- Group-1 (hyporesponsive): 174 patients (66.2\%) with mean $167.30 \pm 52.15 \mathrm{mU} / \mathrm{mL}$ serum antipneumococcal IgG

- Group-2 (immune or responder): 89 patients (33.8\%) with mean $280.30 \pm 52.15 \mathrm{mU} \mathrm{mL}^{-1}$ serum anti-pneumococcal IgG

There were significant differences between serum anti-pneumococcal IgG titers and time post vaccination in two groups. The characteristics of two patient groups (hypo-responsiveness Vs immune or responder) according to anti-pneumococcal IgG titers are presented in Table 2.

\section{DISCUSSION}

Splenectomized $\beta$-thalassemia patients have a high risk of Streptococcus pneumoniae infections, which could be due to the reduced antibody response to bacterial polysaccharide antigens in these patients due to splenectomy (Zarina et al., 2010).

Although pneumococcal immunization in Splenectomized $\beta$-thalassemia patients is recommended (Sheikha et al., 2007), there are few reported studies involving the evaluation of the antibody response to polysaccharide antigens in these patients or the efficacy of pneumococcal vaccination in these patients (Sakran et al., 2010).

Sufficient antibody response to pneumococcal antigens (equal to or more than $250 \mathrm{mU} \mathrm{mL}^{-1}$ ) in Splenectomized $\beta$-thalassemia patients can show the significance of vaccination in order to protect them against pneumococcal infections (Cadili and Gara, 2008; Waghorn, 2001; Austrian, 1977).

The result of the present study indicated that $66.2 \%$ of Splenectomized $\beta$-thalassemia patients were hyporesponsive to pneumococcal antigens, which is in arrangement with the study performed by Rao et al. (1995) showing that $42 \%$ of the vaccinated Splenectomized $\beta$-thalassemia patients were protective to Streptococcus pneumonia. This indicates that measurement of post-vaccination antibody levels can be used to identify the poor responders who most likely are at increased risk of pneumococcal infection.

In the present study, mean anti-pneumococcal $\operatorname{IgG}$ titers in male patients did not differ from female patients. This data shows that anti-pneumococcal IgG titer is independent of sex in these patients.

However, poor responders proved to be unresponsive to booster doses of polysaccharide antigens (Rodriguez-Barradas et al., 1996; Petrasch et al., 1997). Purified polysaccharide antigens result in $T$ cell-independent, type-2 antibody formation and do not elicit memory $\mathrm{B}$ cells. $\mathrm{T}$ cell-independent antibody responses cannot be boosted to produce secondary responses. It is possible that conjugate vaccines (capsular polysaccharides conjugated to carrier proteins) might improve the immune response in nonresponders to PPV: the 7-valent pneumococcal conjugate vaccine has improved the response rate to PPV23 in patients with selective antibody deficiency (Zielen et al., 2000).

The results obtained here suggest that an immunization policy with pneumococcal polysaccharides might help to protect the majority of Splenectomized $\beta$-thalassemia patients against invasive pneumococcal diseases; therefore, we suggest that the vaccine be administered. Nevertheless, some subjects who cannot mount an adequate antibody response to polysasaccharide antigens will remain at significant risk for such infections and should be offered other, prophylactic methods such as immunization with pneumococcal conjugate vaccines.

According to an inverse significant correlation between mean anti-pneumococcal IgG titers and time post splenectomy which was found from this study, indicates a decline of anti-pneumococcal IgG titer along the time. Published data indicate that vaccinated immunocompromised patients, who had a nearly normal antibody response to pneumococcal vaccine and immune patients to Streptococcus pneumonia, will require revaccination to maintain their immunity (Zarina et al., 2010; Orthopoulos et al., 2009). 
It is notable that some factors such as chronic kidney disease and haemodialysis can reduce the immune response to vaccines (Jahromi et al., 2009; 2011) and it has been not investigated between kidney function tests and immunity to pnemococcal vaccine in this research.

\section{CONCLUSION}

Based on the results of this study, there is a need to re-address the approach towards revaccination in this immune-compromised group of patients by administering a booster pneumococcal vaccination in an attempt to recover immunity and reduce morbidity. Further researches with larger samples from other areas of IRAN are recommended for this approach.

\section{ACKNOWLEDGMENT}

This research was funded by the vice-chancellor for research of Jahrom University of Medical Sciences and Health Services. The authors are appreciative to all the patients and their families for their kind cooperation in this research.

\section{REFERENCES}

Ali, D., K. Mehran and A.G. Moghaddam, 2008. Comparative evaluation of renal findings in Betathalassemia major and intermedia. Saudi J. Kidney Dis. Transpl., 19: 206-209. PMID: 18310868

Austrian, R., 1977. Pneumococcal infection and pneumococcal vaccine. N. Engl. J. Med., 297: 938939.

Cadili, A. and C.D. Gara, 2008. Complications of splenectomy. Am. J. Med., 121: 371-275. PMID: 18456028

Gharagozloo, M., M. Karimi and Z. Amirghofran 2009. Double-faced cell-mediated immunity in betathalassemia major: Stimulated phenotype versus suppressed activity. Ann. Hematol., 88: 21-27. PMID: 18690440

Hoe, T.S., A. Lammi and B. Webster, 1994. Homozygous $\beta$-thalassaemia: A review of patients who had splenectomy at the Royal Alexandra Hospital for Children, Sydney. Singapore Med. J., 35: 59-61. PMID: 8009282

Jahromi, A.S., M. Pourahmd, S. Azhdari, G. Manshoori and A. Madani et al., 2011. Immunity to diphtheria in haemodialysis patients. Am. J. Infect. Dis., 7: 20-23. DOI: 10.3844/ajidsp.2011.20.23

Jahromi, A.S., R. Raoofi, M. Sarikhani and A. Madani. 2009. Evaluation of anti-tetanus immunity in haemodialysis patients. Am. J. Immunol., 5: 108112. DOI: $10.3844 /$ ajisp.2009.108.112
Karnon, J., D. Zeuner, J. Brown, A.E. Ades and B. Wonke et al., 1999. Lifetime treatment costs of beta-thalassaemia major. Clin. Lab Haematol., 21: 377-385. PMID: 10671989

Mahmoodi, M., A. Aghamohammadi, N. Rezaei, M. Lessan-Pezeshki and G. Pourmand et al., 2009. Antibody response to pneumococcal capsular polysaccharide vaccination in patients with chronic kidney disease. Eur. Cytokine Netw., 20: 69-74. PMID: 19541592

Orthopoulos, G.V., M.C. Theodoridou, V.A. Ladis, D.K. Tsousis and V.I. Spoulou, 2009. The effect of 23-valent pneumococcal polysaccharide vaccine on immunological priming induced by 7 -valent conjugate vaccine in asplenic subjects with betathalassemia. Vaccine, 27: 350-354. PMID: 19010369

Petrasch, S., O. Kuhnemund, A. Reinacher, M. Uppenkamp and R. Reinert et al., 1997. Antibody responses of splenectomized patients with nonHodgkin's lymphoma to immunization with polyvalent pneumococcal vaccines. Clin. Vaccine Immunol., 4: 635-638.

Rao, S.P., K. Rajkumar, G. Schiffman, N. Desai and C. Unger et al., 1995. Anti-pneumococcal antibody levels three to seven years after first booster immunization in children with sickle cell disease and after a second booster. J. Pediatrics, 127: 590592. DOI: 10.1016/S0022-3476(95)70119-2

Ricerca, B.M., A.D. Girolamo and D. Rund, 2009. Infections in thalassemia and hemoglobinopathies: Focus on therapy-related complications. Mediterr J. Hematol. Infect. Dis., 28: e2009028-e2009028. PMID: 21415996

Rodriguez-Barradas, M.C., J.E. Groover, C.E. Lacke, D.W. Gump and C.J. Lahart et al., 1996. DisIgG antibody to pneumococcal capsular polysaccharide in human immunodeficiency virus-infected subjects: Persistence of antibody in responders, revaccination in nonresponders and relationship of immunoglobulin allotype to response. J. Infect. Dis., 173: 1347-1353. PMID: 8648206

Sakran, W., C. Levin, Y. Kenes, R. Colodner and A. Koren, 2010. Clinical spectrum of serious bacterial infections among splenectomized patients with hemoglobinopathies in Israel: A 37-year follow-up study. Infection, 40: 35-39. DOI: 10.1007/s15010011-0178-5

Sheikha, A.K., Z.T. Salih, K.H. Kasnazan, M.K. Khoshnaw and T. Al-Maliki et al., 2007. Prevention of overwhelming postsplenectomy infection in thalassemia patients by partial rather than total splenectomy. Can. J. Surg., 50: 382-386. 
Waghorn, D.J., 2001. Overwhelming infection in asplenic patients: Current best practice preventive measures are not being followed. J. Clin. Pathol., 54: 214-218. DOI: 10.1136/jcp.54.3.214

Weatherall, D.J. and J.B. Clegg, 2001. The Thalassaemia Syndromes. 4th Edn., Blackwell Science, Oxford, ISBN-10: 0865426643, pp: 846.

Wernette, C.M., C.E. Frasch, D. Madore, G. Carlone and D. Goldblatt et al., 2003. Enzyme-linked immunosorbent assay for quantitation of human antibodies to pneumococcal polysaccharides. Clin. Diagn Lab Immunol., 10: 514-519. PMID: 12853378
Zarina, A.L., K.N. Norazlin, A. Hamidah, D.A. Aziz and S.Z. Zulkifli et al., 2010. Spectrum of infections in splenectomised thalassaemia patients. Med. J. Malaysia, 65: 283-285. PMID: 21901946

Zielen, S., I. Buhring, N. Strnad, J. Reichenbach and D. Hofmann, 2000. Immunogenicity and tolerance of a 7-valent pneumococcal conjugate vaccine in nonresponders to the 23-valent pneumococcal vaccine. Infect. Immun., 68: 1435-1440. 